\title{
IMPACT OF ROWING TRAINING ON QUALITY OF LIFE AND PERCEIVED HEALTH IN FEMALE BREAST CANCER SURVIVORS
}

\author{
Juan Gavala-González ${ }^{1,2}$, Amanda Torres-Pérez ${ }^{2 *}$ and José Carlos Fernández-García ${ }^{2,3}$ \\ 1 Department of Physical Education and Sports, University of Seville, Seville, Spain; jgavala@us.es \\ 2 Researching in Sport Science: Research group (CTS-563) of the Andalusian Research Plan. \\ 3 Department of Didactics of Languages, Arts and Sport, University of Malaga, Andalucía-Tech, IBIMA, Má- \\ laga, Spain; jcg@uma.es \\ * Correspondence: amanda.torresperez@hotmail.com
}

\begin{abstract}
The aim of this study was to determine whether a rowing training program improved the quantity and quality of physical activity and quality of life in female breast cancer survivors (stage I - 4.35\%; II - 30.43\%; III - 52.17\%; and IV - 8.7\%) diagnosed $6.57 \pm 5.02$ years previously, who had undergone a subsequent intervention (preservation $53.52 \%$; total mastectomy $39.13 \%$ and double mastectomy $4.35 \%)$ and had a current mean age of $53.70 \pm 7.88$ years. The participants $(\mathrm{N}=30)$ engaged in a 12-week training program, each week comprising three sessions and each session lasting 60-90 minutes. An anthropometric evaluation was performed before and after the program. The short form of the International Physical Activity Questionnaire (IPAQ-SF) and the Short Form 36 Health Survey (SF-36) were also administered. The results showed statistically significant improvements in levels of physical activity and in the dimensions of quality of life. We can conclude that a 12-week rowing training program tailored to women who have had breast cancer increases physical activity levels, leading to improved health status and quality of life.
\end{abstract}

Keywords: breast cancer; rowing; quality of life; perceived health; IPAQ-SF; SF-36.

\section{Introduction}

Cancer is the second leading cause of death worldwide, representing about 9.6 million deaths in 2018, which means that one in six deaths globally is due to this disease [1,2]. In women, breast cancer is the most common cancer, affecting around 2.1 million women in 2018, i.e., one in four cancers diagnosed is breast cancer [2-4].

The rise in the number of cancer cases diagnosed in recent years has been associated with population growth, closely linked to increased life expectancy and therefore with aging, considering age as a fundamental risk factor for developing cancer. It has also been related to the increase in early detection, improvements in primary care and in early diagnosis programs which, although they lead to higher numbers of cases, are in turn related to a decrease in mortality [4-6].

One third of the diagnosed cancer cases could be prevented if exposure to various lifestyle-related risk factors were eliminated or reduced, such as the consumption of harmful substances such as smoking or alcohol, an unhealthy, high-calorie diet with a high intake of saturated animal fats and sugars, or a sedentary lifestyle [1,4,5,7-9]. A large body of scientific evidence shows that physical activity has positive effects on the general population, improving health status, mood, body composition, quality of life [10-14], and preventing the onset of numerous diseases, including various types of cancer, such as breast cancer $[12,15,16]$.

Physical activity has been associated with a lower risk of developing breast cancer $[9,16-19]$, with a decrease in the probability of relapse and with a higher survival rate 
[16,19-21]. In individuals with cancer, physical activity has benefits for their health: reduced fatigue, improved strength levels, and improved quality of life and physical function $[17,19,22-26]$.

However, despite the evidence supporting physical activity, two out of three cancer patients do not perform the minimum levels of exercise recommended by the American College of Sports Medicine (ACSM), which considers it essential to perform 150 minutes of moderate aerobic activity or 75 minutes of vigorous aerobic activity per week and at least 2 days of resistance training [16,24,27,28].

The relationship between physical activity and breast cancer has been demonstrated in several studies that analyzed and compared the effect of different exercise programs in breast cancer survivors, finding significant improvements in quality of life [29,30], physical function and muscle strength [30,31]. More specifically, the study by Wiskemann et al. (2016) based on a 12-week resistance training program showed gains in muscle strength [32], and in several studies where the training programs combined endurance with aerobic exercise for 12 weeks, the improvements were significant in muscle strength, level of physical activity and quality of life [30,33-37]. In addition, studies on mixed programs combining aerobic and strength exercises [38,39], showed important improvements in aerobic capacity, maximum oxygen consumption, reduction in the percentage of fat mass, muscle strength and, above all, in quality of life. Improvements were also found in physical, psychological, social and quality of life parameters in training programs based on dragon boat rowing in women with breast cancer [25,40-42].

Finally, in studies using the short form of the International Physical Activity Questionnaire (IPAQ-SF) to examine changes in physical activity [36,37] and the Short Form 36 Health Survey (SF-36) for changes in quality of life $[15,31,34,43]$ following physical activity interventions in breast cancer patients, it was found that activity levels increased and the different domains of quality of life improved after completion of the training programs.

The purpose of the present study is to determine the influence of a 12-week rowing training program on level of physical activity and quality of life in women who have survived breast cancer.

\section{Materials and Methods}

\subsection{Design and Participants}

Participants aged $53.7 \pm 7.88$ years were recruited under the condition of having overcome breast cancer. The women were diagnosed $6.57 \pm 5.02$ years earlier, had different stages of disease and had undergone surgery as shown in Table 1.

Table 1. Characteristics of the breast cancer survivor sample.

\begin{tabular}{cccc}
\hline \multicolumn{4}{c}{ Breast (\%) } \\
\hline \multicolumn{4}{c}{ Left: 73.91} \\
\hline \multicolumn{4}{c}{ Stage (\%) } \\
\hline I: 4.35 & III: 30.43 & III: 52.17 & IV : 8.7 \\
\hline \multicolumn{4}{c}{ Surgery (\%) } \\
\hline Preservation: 53.52 & Total Mastectomy: 39.13 & Double Mastectomy: 4.35 \\
\hline
\end{tabular}

After the initial selection, the nature of the study was explained to the participants, indicating that their anonymity would be maintained at all times, following the ethical considerations of the Sport and Exercise Science Research [44], as well as the principles included in the Declaration of Helsinki [45], which define the ethical guidelines for research in human subjects. The University of Malaga assigned the identification number 65-2020-H, which is registered with the Ethics Committee. The participants provided written informed consent and throughout the intervention and afterwards, we acted under the provisions of the Organic Law 3/2018, of December 5, on the Protection of Personal 
Data and Guarantee of Digital Rights, regarding the protection of personal data under Spanish legislation.

\subsection{Instruments}

A Tanita model BC730 scale, accuracy of $0.1 \mathrm{~kg}$, was used to weigh the subjects and to measure height, a SECA model 213 portable stadiometer, accuracy of $0.1 \mathrm{~cm}$. A dualenergy x-ray densitometer (DEXA, Hologic Explorer, United States) was used to assess body fat, lean mass, total fat percentage and total body mass.

The participants also completed the short version of the International Physical Activity (IPAQ-SF) questionnaire to assess physical activity levels. This questionnaire consists of seven questions which have acceptable measurement properties to monitor physical activity levels for adults aged 18 to 65 years in various settings and also reports the number of metabolic equivalents (METS) [46]. Several studies have validated the reliability of using the IPAQ-SF to report the number of METS, obtaining significant results compared to those of other tests such as accelerometry or podometry [47-49].

The SF-36 Health Survey was used to measure self-perceived health. This questionnaire consists of 36 items that report both positive and negative health status covering eight dimensions: physical function, social function, physical role, emotional role, mental health, vitality, bodily pain and general health.

\subsection{Procedure}

The 12-week rowing training program was divided into three parts of 4 weeks each. These stages progressively increased in intensity and were regulated through the participants' subjective perception of effort, using the Börg scale [50].

- Initial phase: mobility, proprioceptive and postural control exercises. Main phase with rowing training. Final phase with stretching. Börg scale 5-6.

- Intermediate phase: mobility, proprioceptive and postural control exercises. Main phase with rowing training. Final phase with stretching. Börg scale 6-7.

- Final phase: mobility, proprioceptive and postural control exercises. Main phase with rowing training. Final phase with stretching. Börg scale 7-8.

Throughout the program, a weekly schedule was established consisting of three training days lasting 60-90 minutes per session. These sessions were supervised by a trainer who ensured attendance, correct execution of the tasks and intensity of the sessions, in addition to excluding from the study those subjects who did not comply with at least $90 \%$ participation. Each of the training sessions had the same structure:

1. Initial component: performed with warm-up, mobility, proprioceptive and postural control exercises, all exercises carried out in a multipurpose room.

2. Main component: performed in the Mediterranean Sea near the port of Malaga (Cruise Terminal/Malagueta Beach) using fixed-bench boats, typical of the Spanish Mediterranean, called Llauts, which are propelled by eight rowers and a coxswain or skipper [51], with each rower holding a single oar.

3. Return to calm: flexibility exercises to relax the musculature and bring the body back to its initial state after exercise.

Both at the beginning and at the end of the program, sessions were held to discuss issues, and the participants were asked to complete the questionnaires and to visit the Human Motricity Laboratory at the University of Malaga for anthropometric (weight and height) and body composition (DEXA) assessments.

\subsection{Data Analysis}

All analyses were performed with IBM SPSS, version 25. The significance level was defined as $p<0.05$. The fit of the different variables to the normal distribution was assessed using both graphic procedures and the Shapiro-Wilk test. 
To examine the differences resulting from the rowing training performed by the participants, the medians of each variable pre- and post-intervention were analyzed using the Wilcoxon test for related samples (paired data). In addition, the graphic analysis of the different variables was carried out using box and whisker plots.

\section{Results}

The descriptive analysis of the different study variables (Table 2), level of physical activity and quality of life are shown below, differentiating between pre-intervention and post-intervention values.

Table 2. Descriptive analysis of the variables pretest and posttest.

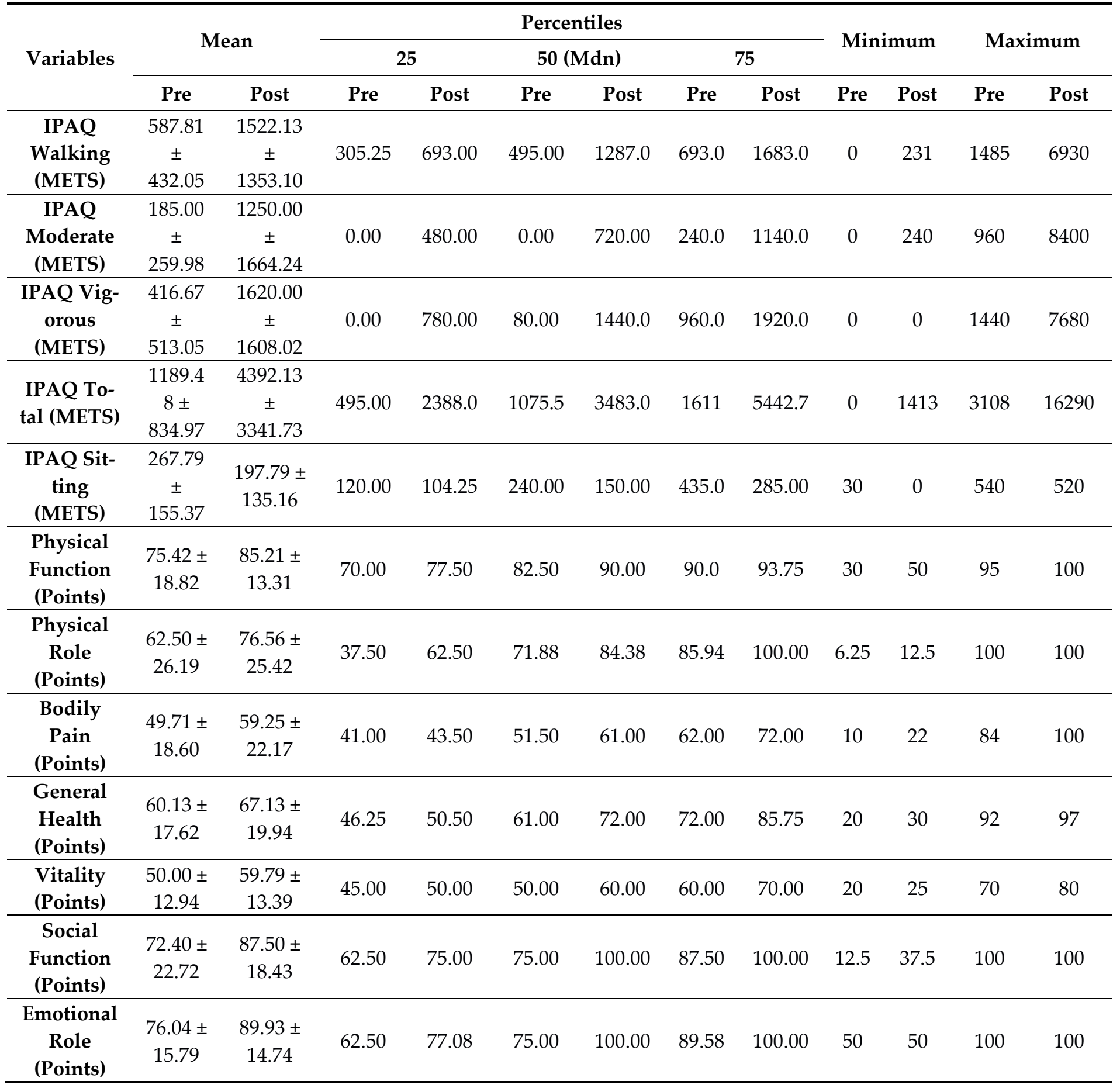




\begin{tabular}{lcccccccccccc}
\hline $\begin{array}{l}\text { Mental } \\
\text { Health } \\
\text { (Points) }\end{array}$ & $\begin{array}{c}58.83 \pm \\
13.88\end{array}$ & $\begin{array}{c}67.00 \pm \\
11.93\end{array}$ & 48.00 & 56.00 & 58.00 & 68.00 & 71.00 & 76.00 & 32 & 36 & 84 & 84 \\
\hline
\end{tabular}

Pre $=$ Pretest $;$ Post $=$ Posttest $;$ Mdn $=$ Median IPAQ $=$ International Physical Activity Questionnaire; METS = metabolic equivalents

For the variables associated with engaging in physical activity obtained from the IPAQ-SF, Table 3 displays the medians of each, as well as the results of the Wilcoxon Test to determine whether significant differences exist between the pretest and posttest data.

Table 3. Statistical analysis of the Physical Activity variables (IPAQ-SF).

\begin{tabular}{cccccc}
\hline \multirow{2}{*}{ Variables } & \multicolumn{2}{c}{ Mdn (50) } & \multicolumn{3}{c}{ Wilcoxon Test } \\
\cline { 2 - 6 } & Pre & Post & T & $\mathbf{z}$ & $\mathbf{p}$ \\
\hline IPAQ Walking (METS) & 495.00 & 1287.00 & 276.00 & -4.201 & $0.000^{* *}$ \\
IPAQ Moderate (METS) & 0.00 & 720.00 & 300.00 & -4.314 & $0.000^{* *}$ \\
IPAQ Vigorous (METS) & 80.00 & 1440.00 & 231.00 & -4.043 & $0.000^{* *}$ \\
IPAQ Total (METS) & 1075.50 & 3483.00 & 300.00 & -4.286 & $0.000^{* *}$ \\
IPAQ Sitting (METS) & 240.00 & 150.00 & 23.50 & -3.075 & $0.002^{*}$ \\
\hline
\end{tabular}

$*=0.05 ;{ }^{* *}=\mathrm{p}<0.001 ;$ Pre $=$ Pretest; Post $=$ Posttest; Mdn = Median; IPAQ = International Physical Activity Questionnaire; METS = metabolic equivalents

The variables IPAQ Walking (Median Difference [Mdn Dif] $=495<1287, \mathrm{z}=-4.201, \mathrm{p}$ $=0.000)$, IPAQ Moderate (Mdn Dif $=0.00<720.00, z=-4.314, p=0.000)$, IPAQ Vigorous $(\mathrm{Mdn}$ Dif $=80.00<1440.00, \mathrm{z}=-4.043, \mathrm{p}=0.000)$, IPAQ Total $(\mathrm{Mdn}$ Dif $=1075.50<3483.00$, $\mathrm{z}=-4.286, \mathrm{p}=0.000)$ and IPAQ Sitting $(\mathrm{Mdn}$ Dif $=240.00>150.00, \mathrm{z}=-3.075, \mathrm{p}=0.002)$ revealed significant differences between pretest and posttest data.

Figure 1 depicts all the physical activity variables, showing improvements after the intervention in levels of Walking, Moderate, Vigorous and Total Physical Activity, all of which are highly significant. The lower value obtained for the IPAQ Sitting variable after the intervention compared to before the intervention indicates the participants were more active and spent less time sitting throughout the week. 


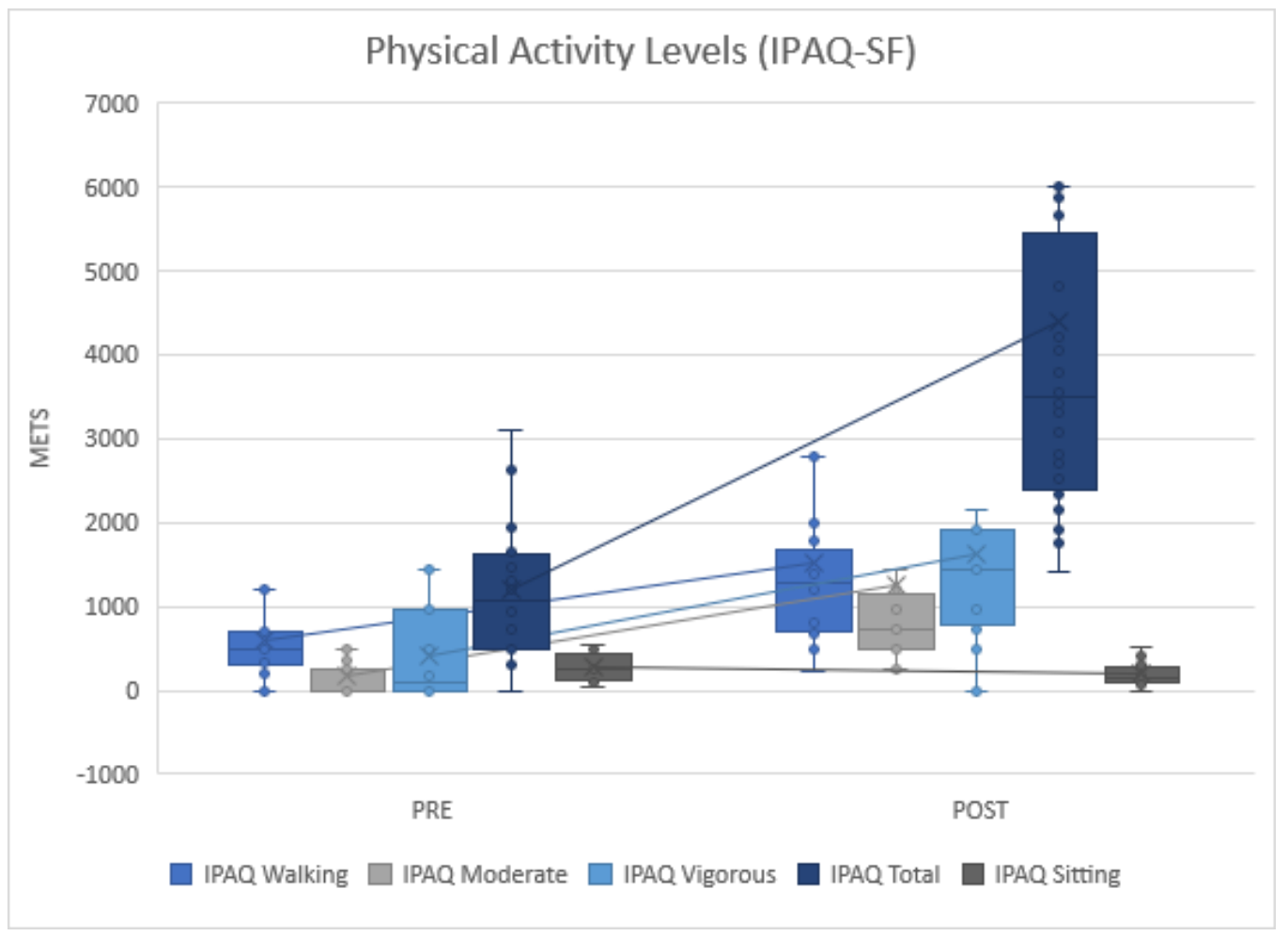

Figure 1. Physical Activity levels (IPAQ-SF); PRE = Pretest; POST = Posttest; METS = metabolic equivalents

Regarding the quality of life of the participants, the differences between the results obtained in the various measurements through the SF-36 questionnaire can be seen in Table 4 .

Table 4. Statistical analysis of the Quality of Life variables (SF-36).

\begin{tabular}{cccccc}
\hline \multirow{2}{*}{ Variables } & \multicolumn{2}{c}{ Mdn (50) } & \multicolumn{3}{c}{ Wilcoxon Test } \\
\cline { 2 - 6 } & Pre & Post & $\mathbf{T}$ & $\mathbf{z}$ & $\mathbf{p}$ \\
\hline Physical Function (Pts) & 82.50 & 90.00 & 117 & -3.256 & $0.001^{*}$ \\
Physical Role (Pts) & 71.88 & 84.38 & 226 & -3.866 & $0.000^{* *}$ \\
Bodily Pain (Pts) & 51.50 & 61.00 & 186.5 & -2.472 & $0.013^{*}$ \\
General Health (Pts) & 61.00 & 72.00 & 188 & -2.006 & $0.045^{*}$ \\
Vitality (Pts) & 50.00 & 60.00 & 232 & -2.879 & $0.004^{*}$ \\
Social Function (Pts) & 75.00 & 100.00 & 130 & -3.247 & $0.001^{*}$ \\
Emotional Role (Pts) & 75.00 & 100.00 & 160 & -3.268 & $0.001^{*}$ \\
Mental Health (Pts) & 58.00 & 68.00 & 180.5 & -2.836 & $0.005^{*}$ \\
\hline
\end{tabular}

$\mathrm{Mdn}=$ Median; Pre = Pretest; Post $=$ Posttest; Pts $=$ Points; $^{*}=\mathrm{p}<0.05 ;{ }^{* *}=\mathrm{p}<0.001$.

The variables Physical Function (Dif Mdn $=82.50<90.00, z=-3.256, p=0.001$ ), Physical Role (Dif Mdn = 71.88 $<84.38, z=-3.866, p=0.000$ ), Bodily Pain (Dif Mdn $=51.50<$ 61.00, $z=-2.472, p=0.013$ ), General Health (Dif Mdn $=61.00<72.00, z=-2.006, p=0.045$ ), Vitality (Dif Mdn $=50.00<60.00, z=-2.879, p=0.004)$, Social Function $(\operatorname{Dif} \operatorname{Mdn}=75.00<$ 100.00, $\mathrm{z}=-3.247, \mathrm{p}=0.001$ ), Emotional Role (Dif Mdn $=75.00<100.00, \mathrm{z}=-3.268, \mathrm{p}=0.001$ ) and Mental Health (Dif Mdn $=58.00<68.00, z=-2.836, p=0.005$ ) show significant differences between the data taken before the training program and after the training program. 
Figure 2 displays the results for the variables associated with quality of life before and after the intervention. All of them (Physical Function, Physical Role, Body Pain, General Health, Vitality, Social Function, Emotional Role and Mental Health) have higher values after the physical activity program, which suggests that perceived physical, emotional and mental health status is improved after the intervention and therefore limits to a lesser extent the level of physical activity, social life and vitality of the participant.

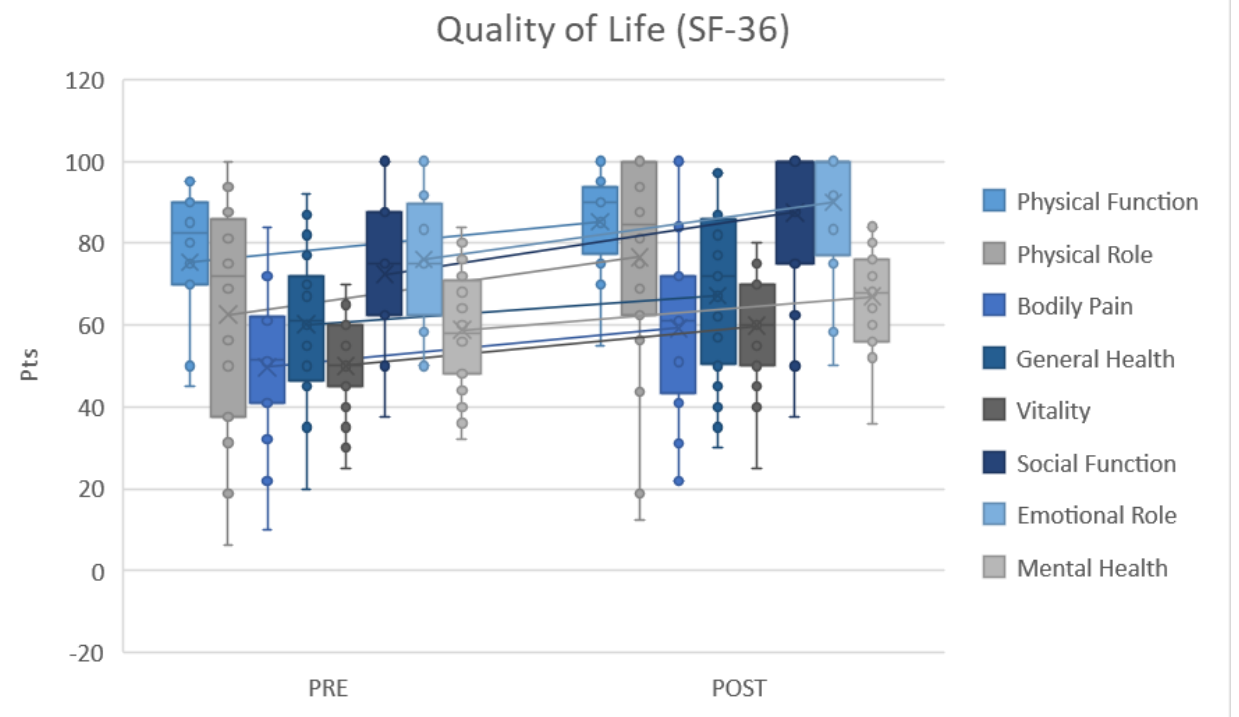

Figure 2. Quality of Life variables (SF-36); Pts = Points; PRE = Pretest; POST = Posttest.

Focusing on some of the quality of life variables, Figure 3 shows the variation in bodily pain. That this value is higher after the intervention may indicate that the participants report less pain in general. In other words, engaging in rowing decreases bodily pain in women who are breast cancer survivors or increases the pain threshold in the women studied.

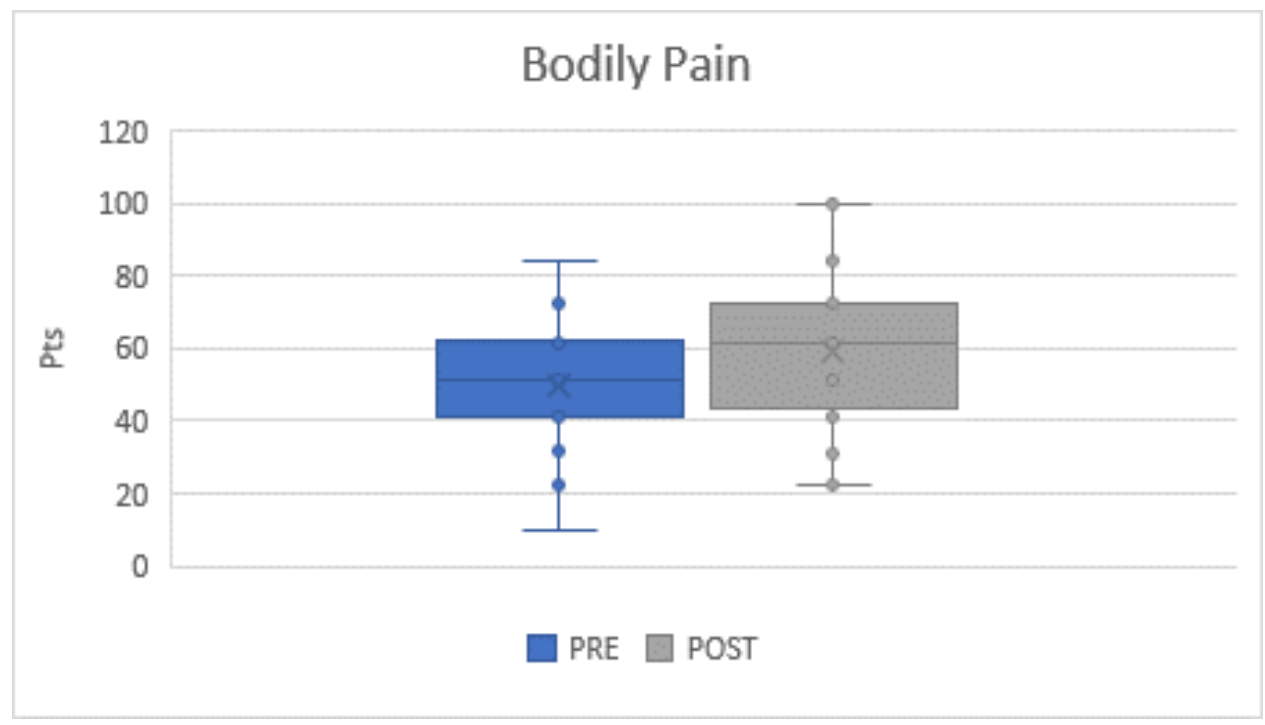

Figure 3. Bodily Pain; Pts = Points; PRE = Pretest; POST = Posttest.

Figure 4 illustrates the improvement after the intervention in the physical role, which indicates that the participants have fewer limitations when performing any physical activity compared to prior to the intervention. This suggests that a 12-week rowing training program, adapted to women who have had breast cancer, helps to improve the perceived ability to perform other activities. 


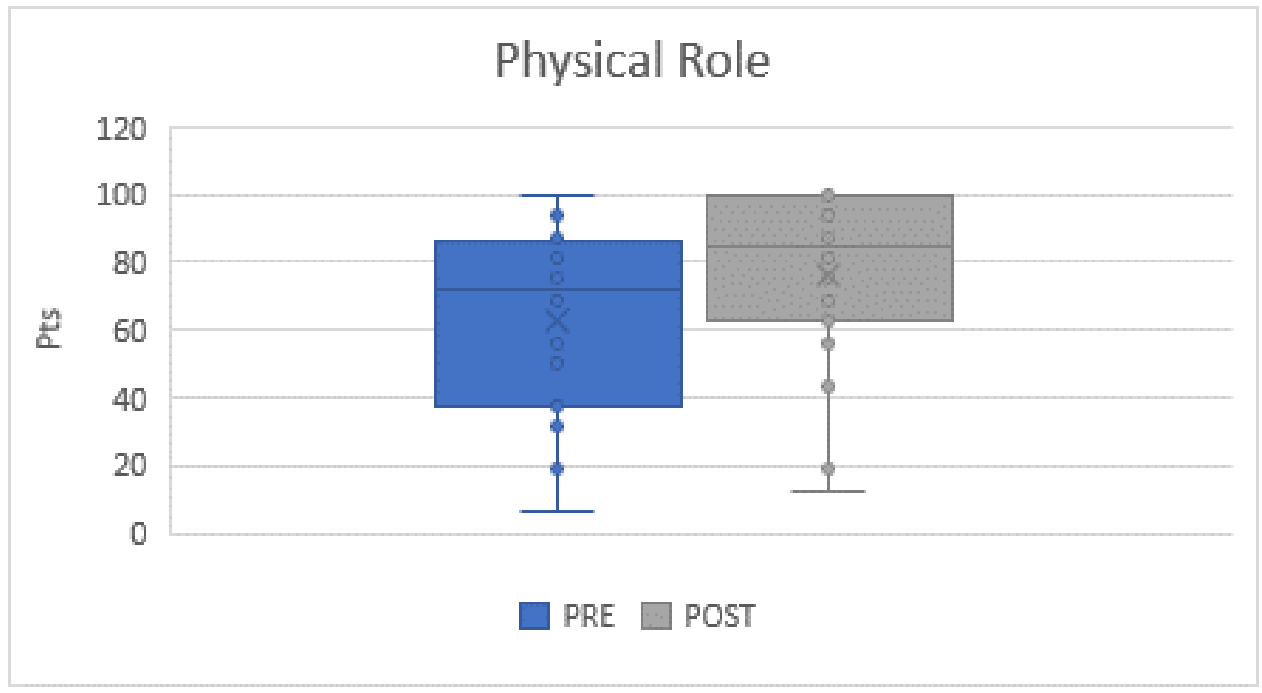

Figure 4. Physical Role; Pts = Points; PRE = Pretest; POST = Posttest .

Finally, in terms of overall perceived health of the participants, a significant improvement was detected after the physical activity intervention (Figure 5), demonstrating that after completing the rowing program, a tendency towards an improved perception of health emerged: The number of women who reported having poor or fair health decreased and those who claimed having "very good health" increased, with $75 \%$ of the participants reporting their health status to be good or very good.

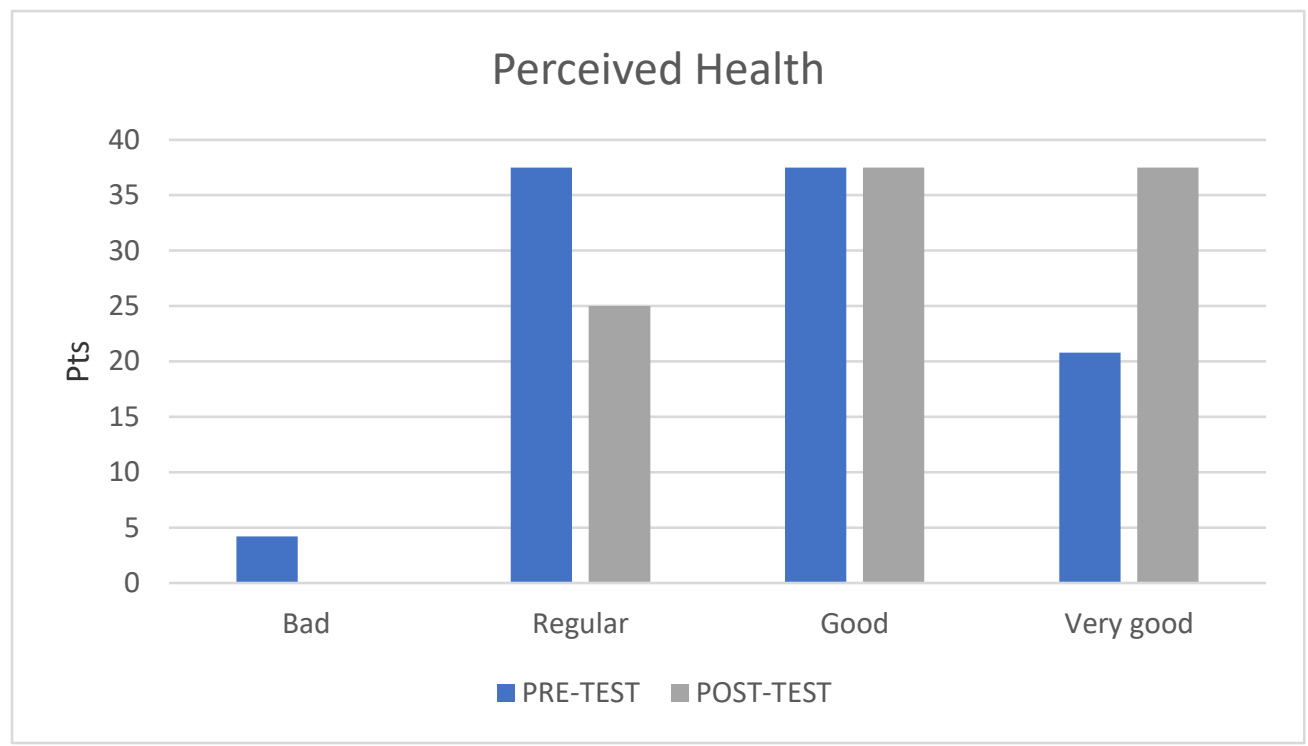

Figure 5. Variation in Perceived Health; Pts = Points.

In summary, after an intervention based on a 12-week rowing training program tailored to women who have had breast cancer, all the variables included, both those concerning level of physical activity and quality of life, showed significant improvements. That is, the participants were more physically active and less sedentary throughout the week and, in addition, their perceived physical, emotional and mental health status improved, which indicates fewer limitations in terms of physical activity, social life and vitality.

\section{Discussion}

Numerous studies have shown that physical activity has multiple benefits for breast cancer survivors, ranging from reducing fatigue $[24,26,30]$ to increasing strength levels and improving quality of life $[19,22,23]$. 
More specifically, upon examining studies that used different types of physical activity programs, the 12-week resistance training program proposed by Wiskemann et al. (2016) reported improvements only in muscle strength [32]. Other programs that combined aerobic and strength exercises for 24 weeks led to improvements in muscle strength, aerobic capacity and only some of the quality of life dimensions [39], while those that combined resistance and aerobic exercises for 16 weeks showed improvements in the quality of life and physical fitness of the participants [34]. Harris (2012) and McDonough et al. (2018) reported that dragon boat rowing [40,41] led to physical, psychological and social improvements in female breast cancer survivors.

Similar results are presented in our study, based on a rowing training program of just 12 weeks duration. We observed improvements in physical activity levels in the participants, with significant increases in walking and moderate, vigorous and total physical activity, as well as a decrease in sedentary time. In addition, we found improvements in all the quality of life dimensions.

In the study by Park et al. (2019), through a training program combining aerobic and resistance exercises, physical activity levels increased after the 12-week intervention, rising in $63.4 \%$ of the participants [36]. It is of interest to compare these results with those of our study, which uses an intervention of the same duration. In our study, overall physical activity levels increased in all the participants after the rowing program with respect to the initial measurement. It should also be noted that prior to the intervention, about $50 \%$ of the participants reported no moderate or vigorous physical activity, whereas afterwards, all the participants reported engaging in moderate physical activity and less than $10 \%$ reported no vigorous activity.

Regarding quality of life parameters, the study by Mascherini et al. (2020) shows improvements in Physical Function, Social Function, General Health and Mental Health after 6 months of training [15] and Di Blasio et al. (2017) after 12 weeks of intervention only found improvements in Physical Function, Physical Role, Bodily Pain and General Health [31]. Dolan et al. (2018) also showed that after a 22-week training program all SF-36 quality of life dimensions improved with the exception of Bodily Pain [43].

The results of the present study demonstrate that rowing training has a greater influence on quality of life in breast cancer survivors than previous studies, as significant improvements were found in all the quality of life parameters after an intervention of shorter duration. This implies that both perceived physical, emotional and mental health status and the perceived ability to perform other activities improved to a greater extent after our rowing-based training program. Indeed, $75 \%$ of the participants reported their health status as good or very good after the intervention, with a considerable increase compared to the initial data.

\section{Conclusions}

While studies have reported improved quality of life and reduced physical inactivity in female breast cancer survivors through training programs such as aerobic, strength, resistance and dragon boat exercises, in the present study, we have shown that an intervention of just twelve weeks in length using rowing training tailored to women who have had breast cancer produced statistically significant improvements in all levels of physical activity and reduced physical inactivity. In addition, the physical, emotional and mental health status of the participants improved, leading to fewer limitations in their daily routines, physical activity, social life and vitality. Our rowing program showed greater benefits in health and quality of life than other studies of various durations. We can therefore conclude that rowing training contributes to increasing daily physical activity and to improving health status, as well as the different dimensions of quality of life in women who have survived breast cancer.

Author Contributions: For research articles with several authors, a short paragraph specifying their individual contributions must be provided. The following statements should be used "Conceptualization, J.G.G. and A.T.P.; methodology, J.C.F.G and J.G.G.; software, A.T.P.; validation, J.C.F.G. and 
J.G.G.; formal analysis, J.C.F.G. and A.T.P..; investigation, J.C.F.G and J.G.G.; resources, J.C.F.G and J.G.G. ; data curation, A.T.P.; writing-original draft preparation, J.G.G. and A.T.P.; writing-review and editing, J.G.G.; A.T.P. and J.C.F.G; visualization, J.G.G.; A.T.P. and J.C.F.G.; supervision, J.C.F.G.; project administration, J.C.F.G and J.G.G.; funding acquisition, J.C.F.G. . All authors have read and agreed to the published version of the manuscript."

Funding: This research was funded by the "Researching in Sport Sciences" research group (CTS563) of the Andalusian Research Plan.

Institutional Review Board Statement: The study was conducted according to the guidelines of the Declaration of Helsinki, and approved by Ethics Committee of University of Málaga (protocol code 65-2020-H and date of approval 30/09/2020).

Informed Consent Statement: Informed consent was obtained from all subjects involved in the study.

Acknowledgments: We would like to thank the Real Club Mediterraneo of Malaga, its rowing captain: Juan Carlos Marfil Rodríguez and the team of the Malaga Dragon Boat BCS for opening their doors to us, giving us all the facilities in the world and for giving us the most important thing: their time and inspiring us with their impetus and energy, thanks to which we can present the first results of this study. To Maria Repice, for her help with the English version of this manuscript. Finally, we would also like to thank Alejandro Sánchez for his participation in the data collection for this study. All authors have read and agreed to the published version of the manuscript.

Conflicts of Interest: The authors declare no conflict of interest.

\section{References}

1. World Health Organization Fact Sheets: Cancer Available online: https://www.who.int/news-room/fact-sheets/detail/cancer (accessed on Aug 10, 2020).

2. International Agency for Research on Cancer (IARC) Cancer Today Available online: https://gco.iarc.fr/today/home (accessed on Aug 10, 2020).

3. World Health Organization Breast Cancer: prevention and control. Available online: https://www.who.int/cancer/detection/breastcancer/en/ (accessed on Aug 12, 2020).

4. Bray, F.; Ferlay, J.; Soerjomataram, I.; Siegel, R.L.; Torre, L.A.; Jemal, A. Global cancer statistics 2018: GLOBOCAN estimates of incidence and mortality worldwide for 36 cancers in 185 countries. CA. Cancer J. Clin. 2018, 68, 394-424, doi:10.3322/caac. 21492 .

5. Sociedad Española de Oncología Médica Las cifras del cáncer en España 2020. Soc. Española Oncol. Médica $2020,36$.

6. World Health Organization Early Cancer Diagnosis saves lives cuts treatments costs Available online: https://www.who.int/es/news/item/03-02-2017-early-cancer-diagnosis-saves-lives-cuts-treatment-costs (accessed on Dec 5, 2020).

7. World Health Organization Prevención del cáncer Available online: https://www.who.int/cancer/prevention/es/ (accessed on Dec 5, 2020).

8. Oliva Anaya, C.A.; Ronquillo, H.A.; García Sierra, J.C. Dieta, obesidad y sedentarismo como factores de riesgo del cáncer de mama. Rev. Cuba. Cirugía 2015, 54, 274-284.

9. World Cancer Research Fund (WCRF); American Institute for Cancer Research (AICR) Diet, Nutrition, Physical Activity and Cancer: a Global Perspective; 2018; ISBN 9781912259465.

10. Loria Calderon, T.M.; Carmona Gómez, C.D. Efecto agudo del baile como ejercicio aeróbico sobre el balance estático en personas mayores de 50 años. Rev. Iberoam. Ciencias la Act. Física y el Deport. 2020, 9, 61-74, doi:10.24310/riccafd.2020.v9i2.8022.

11. Gómez-Cabello, A.; Pardos-Mainer, E.; González-Gálvez, N.; Sagarra-Romero, L. Actividad Física y Calidad de Vida en las Personas Mayores: Estudio Piloto PQS. Rev. Iberoam. Ciencias La Act. Fis. Y El Deport. 2018, 8, 96-109.

12. Warburton, D.E.R.; Bredin, S.S.D. Health benefits of physical activity: a systematic review of current systematic reviews. Curr. Opin. Cardiol. 2017, 32, 541-556, doi:10.1097/HCO.0000000000000437. 
13. Gálvez Fernández, I. Pérdida de Peso y Masa Grasa con Auto-Cargas en Mujeres. Rev. Iberoam. Ciencias la Act. Física y el Deport. 2017, 6, 30-37, doi:10.24310/riccafd.2017.v6i2.3780.

14. Díaz, J.; Muñoz, D.; Cordero, J.C.; Robles, M.C.; Courel-Ibañez, J.; Sánchez-Alcaraz, B.J. Estado de Ánimo y Calidad de Vida en Mujeres Adultas practicantes de Pádel. Rev. Iberoam. Ciencias La Act. Fis. Y El Deport. 2018, 8, 34-43.

15. Mascherini, G.; Tosi, B.; Giannelli, C.; Ermini, E.; Osti, L.; Galanti, G. Adjuvant Therapy Reduces Fat Mass Loss during Exercise Prescription in Breast Cancer Survivors. J. Funct. Morphol. Kinesiol. 2020, 5, 1-10, doi:10.3390/JFMK5030049.

16. Pollán, M.; Casla-Barrio, S.; Alfaro, J.; Esteban, C.; Segui-Palmer, M.A.; Lucia, A.; Martín, M. Exercise and cancer: a position statement from the Spanish Society of Medical Oncology. Clin. Transl. Oncol. 2020, 22, 1710-1729, doi:10.1007/s12094-02002312-y.

17. Graf, C.; Wessely, N. Physical Activity in the Prevention and Therapy of Breast Cancer. Breast Care 2010, 5, 389-394, doi:10.1159/000322650.

18. Wu, Y.; Zhang, D.; Kang, S. Physical activity and risk of breast cancer: a meta-analysis of prospective studies. Breast Cancer Res. Treat. 2013, 137, 869-882, doi:10.1007/s10549-012-2396-7.

19. Johnsson, A.; Broberg, P.; Krüger, U.; Johnsson, A.; Tornberg, Å.B.; Olsson, H. Physical activity and survival following breast cancer. Eur. J. Cancer Care (Engl). 2019, 28, 1-8, doi:10.1111/ecc.13037.

20. Schmidt, M.E.; Chang-Claude, J.; Vrieling, A.; Seibold, P.; Heinz, J.; Obi, N.; Flesch-Janys, D.; Steindorf, K. Association of prediagnosis physical activity with recurrence and mortality among women with breast cancer. Int. J. Cancer 2013, 133, 14311440, doi:10.1002/ijc.28130.

21. Ibrahim, E.M.; Al-Homaidh, A. Physical activity and survival after breast cancer diagnosis: Meta-analysis of published studies. Med. Oncol. 2011, 28, 753-765, doi:10.1007/s12032-010-9536-x.

22. Fong, D.Y.T.; Ho, J.W.C.; Hui, B.P.H.; Lee, A.M.; Macfarlane, D.J.; Leung, S.S.K.; Cerin, E.; Chan, W.Y.Y.; Leung, I.P.F.; Lam, S.H.S.; et al. Physical activity for cancer survivors: meta-analysis of randomised controlled trials. BMJ 2012, 344, 1-14, doi:10.1136/bmj.e70.

23. Pennington, K.P.; McTiernan, A. The role of physical activity in breast and gynecologic cancer survivorship. Gynecol. Oncol. 2018, 149, 198-204, doi:10.1016/j.ygyno.2018.01.020.

24. Mascherini, G.; Tosi, B.; Giannelli, C.; Grifoni, E.; Degl'Innocenti, S.; Galanti, G. Breast cancer: effectiveness of a one-year unsupervised exercise program. J. Sports Med. Phys. Fitness 2018, 59, 283-289, doi:10.23736/S0022-4707.18.08131-8.

25. Gavala-González, J.; Gálvez-Fernández, I.; Mercadé-Melé, P.; Fernández-García, J.C. Rowing training in breast cancer survivors: A longitudinal study of physical fitness. Int. J. Environ. Res. Public Health 2020, 17, 1-12, doi:10.3390/ijerph17144938.

26. Furmaniak, A.; Menig, M.; Markes, M. Exercise for women receiving adjuvant therapy for breast cancer. Cochrane Database Syst. Rev. 2016, doi:10.1002/14651858.CD005001.pub3.www.cochranelibrary.com.

27. de Boer, M.C.; Wörner, E.A.; Verlaan, D.; van Leeuwen, P.A.M. The Mechanisms and Effects of Physical Activity on Breast Cancer. Clin. Breast Cancer 2017, 17, 272-278, doi:10.1016/j.clbc.2017.01.006.

28. Campbell, K.L.; Winters-Stone, K.M.; Wiskemann, J.; May, A.M.; Schwartz, A.L.; Courneya, K.S.; Zucker, D.S.; Matthews, C.E.; Ligibel, J.A.; Gerber, L.H.; et al. Exercise Guidelines for Cancer Survivors: Consensus Statement from International Multidisciplinary Roundtable. Med. Sci. Sports Exerc. 2019, 51, 2375-2390, doi:10.1249/MSS.0000000000002116.

29. Mishra, S.I.; Scherer, R.W.; Snyder, C.; Geigle, P.; Gotay, C. Are Exercise Programs Effective for Improving Health-Related Quality of Life Among Cancer Survivors? A Systematic Review and Meta-Analysis. Oncol. Nurs. Forum 2014, 41, E326-E342, doi:10.1188/14.ONF.E326-E342.

30. Courneya, K.S.; McKenzie, D.C.; Mackey, J.R.; Gelmon, K.; Friedenreich, C.M.; Yasui, Y.; Reid, R.D.; Cook, D.; Jespersen, D.; Proulx, C.; et al. Effects of Exercise Dose and Type During Breast Cancer Chemotherapy: Multicenter Randomized Trial. J. Natl. Cancer Inst. 2013, 105, 1821-1832, doi:10.1093/jnci/djt297.

31. Di Blasio, A.; Morano, T.; Cianchetti, E.; Gallina, S.; Bucci, I.; Di Santo, S.; Tinari, C.; Di Donato, F.; Izzicupo, P.; Di Baldassarre, 
A.; et al. Psychophysical health status of breast cancer survivors and effects of 12 weeks of aerobic training. Complement. Ther. Clin. Pract. 2017, 27, 19-26, doi:10.1016/j.ctcp.2017.01.004.

32. Wiskemann, J.; Schmidt, M.E.; Klassen, O.; Debus, J.; Ulrich, C.M.; Potthoff, K.; Steindorf, K. Effects of 12-week resistance training during radiotherapy in breast cancer patients. Scand. J. Med. Sci. Sport. 2016, 27, 1500-1510, doi:10.1111/sms.12777.

33. Soriano-Maldonado, A.; Carrera-Ruiz, Á.; Díez-Fernández, D.M.; Esteban-Simón, A.; Maldonado-Quesada, M.; Moreno-Poza, N.; García-Martínez, M.D.M.; Alcaraz-García, C.; Vázquez-Sousa, R.; Moreno-Martos, H.; et al. Effects of a 12-week resistance and aerobic exercise program on muscular strength and quality of life in breast cancer survivors: Study protocol for the EFICAN randomized controlled trial. Medicine (Baltimore). 2019, 98, 1-9, doi:10.1097/MD.0000000000017625.

34. Dieli-Conwright, C.M.; Courneya, K.S.; Demark-Wahnefried, W.; Sami, N.; Lee, K.; Sweeney, F.C.; Stewart, C.; Buchanan, T.A.; Spicer, D.; Tripathy, D.; et al. Aerobic and resistance exercise improves physical fitness, bone health, and quality of life in overweight and obese breast cancer survivors: A randomized controlled trial. Breast Cancer Res. 2018, 20, 1-10, doi:10.1186/s13058-018-1051-6.

35. Thomas, G.A.; Cartmel, B.; Harrigan, M.; Fiellin, M.; Capozza, S.; Zhou, Y.; Ercolano, E.; Gross, C.P.; Hershman, D.; Ligibel, J.; et al. The effect of exercise on body composition and bone mineral density in breast cancer survivors taking aromatase inhibitors. Obesity 2017, 25, 346-351, doi:10.1002/oby.21729.

36. Park, S.W.; Lee, I.; Kim, J. Il; Park, H.; Lee, J.D.; Uhm, K.E.; Hwang, J.H.; Lee, E.S.; Jung, S.Y.; Park, Y.H.; et al. Factors associated with physical activity of breast cancer patients participating in exercise intervention. Support. Care Cancer 2019, 27, 1747-1754, doi:10.1007/s00520-018-4427-3.

37. Uhm, K.E.; Yoo, J.S.; Chung, S.H.; Lee, J.D.; Lee, I.; Kim, J. Il; Lee, S.K.; Nam, S.J.; Park, Y.H.; Lee, J.Y.; et al. Effects of exercise intervention in breast cancer patients: is mobile health (mHealth) with pedometer more effective than conventional program using brochure? Breast Cancer Res. Treat. 2017, 161, 443-452, doi:10.1007/s10549-016-4065-8.

38. Smith, T.M.; Broomhall, C.N.; Crecelius, A.R. Physical and Psychological Effects of a 12-Session Cancer Rehabilitation Exercise Program. Clin. J. Oncol. Nurs. 2016, 20, 653-659, doi:10.1188/16.CJON.653-659.

39. De Luca, V.; Minganti, C.; Borrione, P.; Grazioli, E.; Cerulli, C.; Guerra, E.; Bonifacino, A.; Parisi, A. Effects of concurrent aerobic and strength training on breast cancer survivors: a pilot study. Public Health 2016, 136, 126-132, doi:10.1016/j.puhe.2016.03.028.

40. Harris, S.R. Were all in the same boat: A review of the benefits of dragon boat racing for women living with breast cancer. Evidence-based Complement. Altern. Med. 2012, 2012, 1-8, doi:10.1155/2012/167651.

41. McDonough, M.H.; Patterson, M.C.; Weisenbach, B.B.; Ullrich-French, S.; Sabiston, C.M. The difference is more than floating: factors affecting breast cancer survivors' decisions to join and maintain participation in dragon boat teams and support groups. Disabil. Rehabil. 2018, 41, 1788-1796, doi:10.1080/09638288.2018.1449259.

42. Fong, A.J.; Saxton, H.R.; Kauffeldt, K.D.; Sabiston, C.M.; Tomasone, J.R. "We're all in the same boat together": exploring quality participation strategies in dragon boat teams for breast cancer survivors. Disabil. Rehabil. 2020, 0, 1-12, doi:10.1080/09638288.2020.1733676.

43. Dolan, L.B.; Barry, D.; Petrella, T.; Davey, L.; Minnes, A.; Yantzi, A.; Marzolini, S.; Oh, P. The Cardiac Rehabilitation Model Improves Fitness, Quality of Life, and Depression in Breast Cancer Survivors. J. Cardiopulm. Rehabil. Prev. 2018, 38, 246-252, doi:10.1097/HCR.0000000000000256.

44. Harriss, D.; Macsween, A.; Atkinson, G. Standards for Ethics in Sport and Exercise Science Research. Int. J. Sports Med. 2017, $38,1126-1131$.

45. Ebihara, A. World medical association declaration of Helsinki. Japanese Pharmacol. Ther. 2000, $28,983-986$.

46. Barrera, R. Cuestionario Internacional de actividad física (IPAQ). Rev. Enfermería del Trab. 2017, 7, 49-54.

47. Kathleen, Y.; Wolin, D.; Heil, S.; Charles, E.; Gary, G. Validation of the International Physical Activity Questionnaire-Short Among Blacks. J Phys Act Heal. 2008, 5, 746-760. 
48. Cleland, C.; Ferguson, C.; Ellis, C.; Hunter, R. Validity of the International Physical Activity Questionnaire (IPAQ) for assessing moderate-to-vigorous physical activity and sedentary behaviour of older adults in the United Kingdom. BMC Med Res Methodol. 2018, 18, 176.

49. Kurtze, N.; Rangul, V.; Hustvedt, B.E. Reliability and validity of the international physical activity questionnaire in the NordTrøndelag health study (HUNT) population of men. BMC Med. Res. Methodol. 2008, 8.

50. Börg, G. Psychophysical bases of perceived exertion. Med. Sci. Sports Exerc. 1982, 14, 377-381, doi:10.1249/00005768198205000-00012.

51. Gavala-González, J. Las modalidades del remo: el remo en banco fijo. Available online: http://tv.us.es/las-modalidades-delremo-el-remo-en-banco-fijo/ (accessed on Jan 12, 2021). 